\title{
The Astrocyte: Powerhouse and Recycling Center
}

\author{
Bruno Weber ${ }^{1}$ and L. Felipe Barros ${ }^{2}$ \\ ${ }^{1}$ University of Zürich, Institute of Pharmacology and Toxicology, 8057 Zürich, Switzerland \\ ${ }^{2}$ Centro de Estudios Científicos, Casilla 1469, Valdivia, Chile \\ Correspondence: bweber@pharma.uzh.ch; fbarros@cecs.cl
}

Brain metabolism is characterized by fuel monodependence, high-energy expenditure, autonomy from the rest of body, local recycling, and marked division of labor between cell types. Although neurons spend most of the brain's energy on signaling, astrocytes bear the brunt of the metabolic load, controlling the composition of the interstitial fluid, supplying neurons with energy substrates and precursors for biosynthesis, and recycling neurotransmitters, oxidized scavengers, and other waste products. Outstanding questions in this field are the role of oligodendrocytes, the metabolic behavior of the different subtypes of astrocytes during development and disease, and the emerging notion that metabolism may participate directly in information processing.

$T^{\mathrm{h}}$ he energy requirements of the central nervous system (CNS) are very high compared with those of other organs. Although the brain accounts for merely $2 \%$ of body weight, it receives $\sim 15 \%$ of cardiac output, and uses $20 \%$ of the oxygen and $25 \%$ of the glucose of the total body turnover (Magistretti 2008). A special microarchitecture has evolved to support this extreme need, in which glial cells play a central role (Fig. 1). The microvasculature consists of a complex and dense network of highly interconnected blood vessels (Weber et al. 2008; Blinder et al. 2013) to ensure adequate delivery of oxygen and glucose. Although oxygen diffuses freely into the parenchyma, glucose and other hydrophilic energy substrates are translocated across membranes via specific transporter proteins (Fig. 1). The astrocyte is a polarized cell. One set of astrocytic processes ensheaths the vasculature and a second set reaches toward the syn- apse, the site of highest energy demand (Harris et al. 2012). Much of the ATP produced in the brain is spent by neurons on the recovery of ion gradients challenged by postsynaptic potentials, with a smaller investment in action potentials and neurotransmitter recycling (Harris et al. 2012). Astrocytes consume considerable energy for their own needs and the cycling of metabolically relevant substances for neurons. These metabolic processes in astrocytes and neurons are the basis for brain mapping using functional magnetic resonance imaging and positron emission tomography (PET) - methods that capture local metabolism either directly or indirectly via hemodynamic changes (Magistretti 2008; Belanger et al. 2011a).

Levels of energy consumption in the whole brain are almost constant. However, individual neurons can increase their consumption dramatically. For example, a striatal neuron may

Editors: Ben A. Barres, Marc R. Freeman, and Beth Stevens

Additional Perspectives on Glia available at www.cshperspectives.org

Copyright (C) 2015 Cold Spring Harbor Laboratory Press; all rights reserved; doi: 10.1101/cshperspect.a020396

Cite this article as Cold Spring Harb Perspect Biol 2015;7:a020396 


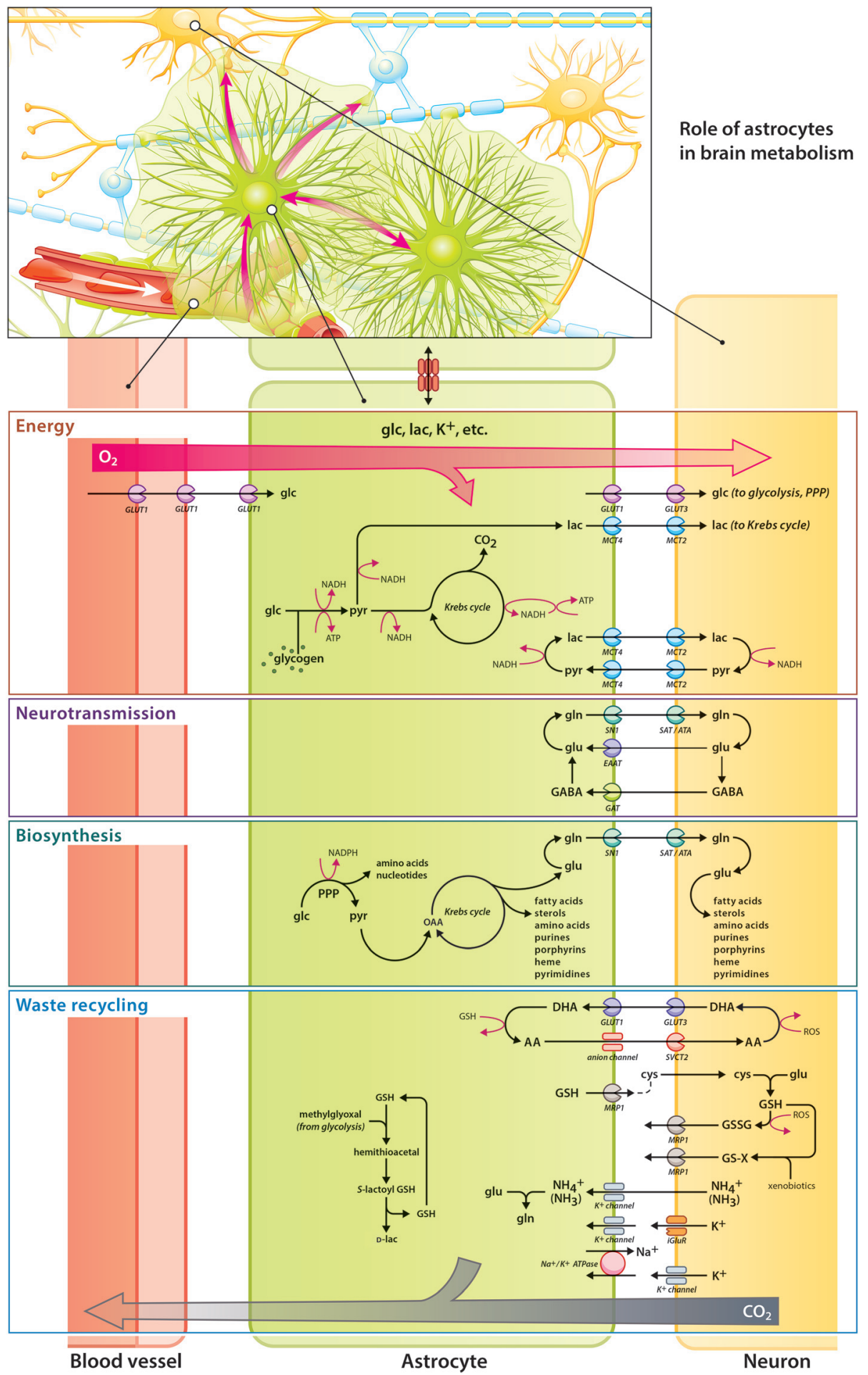

Figure 1. Overview of astrocytic metabolism. (Inset) Astrocytes (green) reside between blood vessels (red) and neurons (yellow). Neurons and oligodendrocytes (blue) are not in direct contact with vessels. Astrocytes form metabolic domains and are coupled by gap junctions, through which they exchange metabolites and ions. Energy: The main energy substrate of the brain is glucose (glc), which crosses the endothelium and enters astrocytes via the glucose transporter GLUT1. Glucose is converted by glycolysis into pyruvate (pyr), which is oxidized to $\mathrm{CO}_{2}$ by the mitochondrial Krebs cycle, producing NADH and then ATP. Pyruvate also generates lactate (lac), which is shuttled via monocarboxylate transporters MCT4 and MCT2 to be used as an energy substrate by neurons. Astrocytes store energy in the form of glycogen. (Legend continues on following page.) 
jump from electric silence to a firing rate of $40 \mathrm{~Hz}$ within milliseconds, demanding an estimated 30-fold increase in fuel supply (Attwell and Laughlin 2001). The large dynamic range of energy metabolism at the single-cell level is unique to nervous tissue. It could be argued that a general principle of design is the dampening of this dynamic range to make it sustainable in terms of fuel and oxygen delivery. One dampening strategy is "sparse coding," whereby information is encoded by only a few neurons at any given point in time (Kording et al. 2003; Olshausen and Field 2004). Astrocytes also help to reduce the metabolic impact of neuronal signaling by diluting the individual demands of synapses in space and time.

Astrocytes are the metabolic workhorses of the brain. In addition to catering for themselves, astrocytes subsidize neurons, oligodendrocytes, and possibly microglia by providing energy and building blocks for biosynthesis. Astrocytes energize trans-cellular cycles, inactivate toxic waste, and express complex biochemical pathways, including synthesis, assembly, and degradation of enzymes and ancillary proteins, all of which demand energy and information. Moreover, metabolites are water soluble, requiring osmotically obliged water and, therefore, space. Relieved from metabolic duties, neurons can allocate more of their resources to information processing.

\section{MORPHOLOGY OF ASTROCYTES AND THEIR ROLE AS INTERFACE CELLS}

For understanding metabolism, neurons, glial cells, and the cerebral vasculature have to be considered a tightly coupled functional unit. Astrocytes are responsible for the cohesion of this unit (Fig. 1). They are spongiform cells with a central cell body and a dense radial arrangement of prolongations parceling the neuropil into largely nonoverlapping domains. It is estimated that each astrocyte enwraps about four neuronal somata, one or two capillaries, and $10^{5}$ synapses (Bushong et al. 2002; Halassa et al. 2007; Oberheim et al. 2008). Astrocytes cover virtually the entire basal lamina of the cerebral vasculature (Mathiisen et al. 2010) with delicate processes termed "perivascular endfeet" (Reichenbach 1989). They also extend peripheral processes (Derouiche and Frotscher 2001) that make close contact with neurons at somata, dendrites, and axons. The term "tripartite synapse" (Araque et al. 1999) comes from the fact that most of the synapses, pre- and postsynapse, are touched

Figure 1. (Continued) A fast mechanism of neuronal energization is redox cycling, whereby astrocytic lactate is exchanged for neuronal pyruvate, with the net transfer of one energy-rich NADH per cycle. Neurons capture glucose via the glucose transporter GLUT3 to be metabolized via glycolysis and the pentose phosphate pathway (PPP) to promote antioxidation. Neurotransmission: Glutamate and $\gamma$-aminobutyric acid (GABA) are captured by astrocytic excitatory amino acid transporters (EAAT) and GAT, respectively, converted into glutamine and shuttled back to neurons for recycling via multiple astrocytic and neuronal transporters (SN1, SAT/ATA, and others). Biosynthesis: Glucose diverted through the astrocytic PPP generates NADPH and precursors for the synthesis of nucleotides and amino acids. Pyruvate is carboxylated into the Krebs cycle intermediate oxaloacetate (OAA), which is a precursor of multiple biosynthetic pathways in astrocytes and, through shuttling of glutamine, is also the main precursor for neuronal biosynthesis. Waste recycling: Reactive oxygen species (ROS) in neurons are scavenged by ascorbate (AA) with the production of dehydroascorbic acid (DHA), which diffuses through the glucose transporters toward astrocytes to be recycled into AA, and is returned to neurons via anion channels and the SVCT2. Glutathione (GSH) reacts with ROS to generate glutathione disulfide (GSSG), or with xenobiotics to generate conjugated glutathione (GS-X), both of which are discarded via multidrug resistance proteins (MDR). GSH synthesized and released by astrocytes is cleaved in the interstice to cysteine, which controls the neuronal synthesis of GSH. Ammonia $\left(\mathrm{NH}_{3}\right)$ released by the deamidation of glutamine into glutamate leaves neurons by an unknown pathway and is captured as ammonium $\left(\mathrm{NH}_{4}^{+}\right)$by $\mathrm{K}^{+}$channels in astrocytes, where it is recycled by glutamine synthase. Some nitrogen is returned to astrocytes in the form of alanine and other amino acids (not shown). $\mathrm{K}^{+}$released by neurons during synaptic activity enters astrocytes via $\mathrm{K}^{+}$channels and the $\mathrm{Na}^{+} / \mathrm{K}^{+}$ATPase. Methylglyoxal is a side product of glycolysis, which is detoxified mostly in astrocytes by the glyoxalase system. 
by astrocytic processes (Ventura and Harris 1999). The synapse-astrocyte interface has attracted much attention in relation to neurotransmission (Halassa and Haydon 2010), but it is also of paramount importance for metabolism. The astrocyte removes the neurotransmitter glutamate from the synapse through high-affinity surface transporters, triggering various intracellular metabolic events, which are described elsewhere in this article. The spatial relationship between astrocytes and synapses is complex (Bernardinelli et al. 2014a). Coverage of individual synapses by astrocytic processes varies across brain regions, with this being 100\% in cerebellum (Grosche et al. 1999) and only $29 \%$ in neocortex (Spacek 1985). The degree of coverage is dynamic and dependent on synaptic activity (Bernardinelli et al. 2014b) and modulates local levels of glutamate (Oliet et al. 2001), as well as its cotransmitter D-serine (Panatier et al. 2006). Conceivably, coverage may also modulate the metabolic exchange between astrocytes and neurons.

Many textbooks and reviews have reported that the cerebral vasculature, particularly in the neocortex, is constructed according to functional neuronal units, such as whisker barrels or cortical columns, in general. However, this notion is not supported by recent quantitative analyses of the cerebral cortical vasculature (Tsai et al. 2009; Keller et al. 2011; Hirsch et al. 2012; Blinder et al. 2013). Astrocytic networks, however, do seem to be organized according to neuronal functional units. Astrocytes are coupled by gap junctions, through which metabolites are exchanged (Giaume et al. 2010). This metabolic coupling is confined to individual barrels, suggesting that astrocytes, rather than the vascular network, are responsible for microscopic distribution of energy substrates (Houades et al. 2008; Giaume et al. 2010; Roux et al. 2011). The astrocytic response to various forms of CNS insults includes a significant remodeling of gap junctional communication between astrocytes ( $\mathrm{Li}$ et al. 1998; Oberheim et al. 2008; Giaume et al. 2010). Around the large pial and diving vessels, astrocytes define the VirchowRobin space. This perivascular space is a clearing route for interstitial solutes, a role played by the lymphatic system for the rest of the body (Iliff et al. 2012, 2013; Iliff and Nedergaard 2013; Xie et al. 2013). This so-called glymphatic system consists of a para-arterial influx route, a paravenous clearance route, and a trans-parenchymal pathway facilitated by the astrocytic aquaporin-4 water channel (Iliff and Nedergaard 2013). Because of the dominance of diffusion over short distances, the glymphatic system is likely to play a minor role in local metabolism. However, it may prove relevant for convective transfer between distant regions of the brain, particularly for large protein-bound metabolites, such as cholesterol.

\section{METABOLIC PATHWAYS AND COMPARTMENTS}

The blood-brain barrier provides protection against circulating toxins (Obermeier et al. 2013), behavioral stability in the face of starvation and disease, and the possibility of metabolic specialization, for example, the co-option of the amino acid glutamate for the purposes of neurotransmission. A significant trade-off is that complex and energetically expensive chemical reactions need to be performed "in-house." Neurons are deficient in several metabolic pathways, which are correspondingly stronger in astrocytes, including the production of building blocks for biosynthesis (Yu et al. 1983; HerreroMendez et al. 2009), antioxidation (Schmidt and Dringen 2012), and waste disposal (Bak et al. 2006; Belanger et al. 2011b). There are no metabolic reactions in astrocytes that are not also present in other cell types of the body. The uniqueness of astrocytic metabolism stems from its intimate and heavily biased relationship with the super specialized neuron, in a context of relative insulation from the circulation.

Metabolic processes, occurring within neurons and astrocytes, are distributed between membrane compartments and are the work of enzymes and transporters. Whereas enzymes transform molecules, transporters move them between compartments. As the control of flux is distributed among multiple nodes of the metabolic network, specific enzymes or transporters are no longer considered to be rate limiting. 
Mitochondria, the endoplasmic reticulum, and other membrane-bound organelles host specific reactions, integrated with the rest of the network through exchange with the cytosol. The nucleus is well connected to the cytosol, behaving as a metabolic buffer. The high-diffusion coefficient and high prevailing concentration of most metabolites, together with the slow rate of enzymes, indicates that the cytosol should be a well-mixed compartment (Barros and Martinez 2007; Martinez et al. 2010), a prediction confirmed for glucose in cultured astrocytes (Kreft et al. 2013). However, a recent study of astrocytes in situ revealed that diffusion in endfeet is 20 times slower than in the rest of the cell (Nuriya et al. 2013), which may determine metabolic compartmentation within the cytosol of single astrocytes, particularly for low-concentration molecules like AMP, NADH, and some glycolytic intermediates.

\section{Energy Uptake, Storage, and Delivery}

The adult mammalian brain is energized by the oxidation of glucose (Siesjö 1978). This fuel monodependence has been explained by the inability of albumin-bound fatty acids to cross the blood-brain barrier and the fact that ATP production requires less oxygen from glucose than from fat. Minor substrates, like lactate and ketone bodies, may become significant if their blood levels are elevated, as occurs in strenuous exercise or when fasting (Dalsgaard et al. 2004; Yellen 2008; Rasmussen et al. 2011). Glucose enters the brain via the endothelial transporter GLUT1 and is then captured by astrocytic endfeet, which are also rich in GLUT1 (Kacem et al. 1998). The activity of the astrocytic GLUT1 is acutely stimulated by glutamate (Loaiza et al. 2003; Porras et al. 2008; Chuquet et al. 2010), a mechanism coupling synaptic activity to fuel supply. The paracellular route is seemingly minor, as endfeet wrap $99.7 \%$ of the capillary surface (Mathiisen et al. 2010), and even water requires astrocytic channels to enter the parenchyma (Haj-Yasein et al. 2011). However, the barrier function of endfeet decreases under pathological conditions and may conceivably be a physiologically regulated variable (Nuriya et al. 2013). Unlike muscle cells and adipocytes, astrocytes maintain a substantial pool of glucose (Bittner et al. 2010, 2011; Prebil et al. 2011; Ruminot et al. 2011). Glucose may leave astrocytes at the perisynaptic processes via GLUT1, which by virtue of its relatively low affinity for glucose is similarly equipped to facilitate influx and efflux. Neurons, on the other hand, express GLUT3, a higher affinity transporter that performs better in the influx mode (Barros and Deitmer 2010).

Astrocytes consume more glucose than neurons in cultured cells and tissue slices (BouzierSore et al. 2003, 2006; Barros et al. 2009b; Jakoby et al. 2013), although mitochondrial oxidative phosphorylation, the ATP harvesting phase of metabolism, is somewhat weaker in astrocytes (Hyder et al. 2006), a deficit explained at both transcriptional (Lovatt et al. 2007; Cahoy et al. 2008) and posttranslational levels (HerreroMendez et al. 2009; Halim et al. 2010). This mismatch produces a chronic surplus of pyruvate, which is exported as lactate, an efficient oxidative fuel for neurons in vitro and in vivo (Schurr et al. 1988; Bouzier-Sore et al. 2006; Wyss et al. 2011). In neurons, glycolysis is blocked at the level of phosphofructokinase (PFK) by tonic proteosomal degradation of PFK2 (HerreroMendez et al. 2009; Fernandez-Fernandez et al. 2012). Avectorial flux is thus generated, termed the astrocyte-neuron lactate shuttle (ANLS) (Pellerin and Magistretti 1994). Glycolysis in astrocytes is acutely modulated by two parallel readouts of neuronal activity: glutamate (Pellerin and Magistretti 1994) and $\mathrm{K}^{+}$(Bittner et al. 2011). The effect of $\mathrm{K}^{+}$develops within seconds, is quickly reversible, and is mediated by the $\mathrm{Na}^{+}$/bicarbonate cotransporter NBCe1 (Ruminot et al. 2011). Stimulation by glutamate develops within minutes, persists long after removal, and is mediated by $\mathrm{Na}^{+} /$glutamate cotransporters (Pellerin and Magistretti 1994; Voutsinos-Porche et al. 2003; Bittner et al. 2011). Both mechanisms require an active $\mathrm{Na}^{+} /$ $\mathrm{K}^{+}$ATPase pump (Pellerin and Magistretti 1994; Bittner et al. 2011). Glutamate may further promote lactate production by inhibiting astrocytic respiration (Azarias et al. 2011). The driving forces for the ANLS are the gradients in 
pyruvate concentration and $\mathrm{NADH} / \mathrm{NAD}^{+}$ ratio between astrocytes and neurons. The combination of low-affinity isoforms of lactate dehydrogenase (LDH5) and the monocarboxylate transporter (MCT4) in astrocytes, and highaffinity isoforms LDH1 and MCT2 in neurons act as a rectifier, facilitating a one-way flux from astrocytes to neurons (Fig. 1) (Aubert et al. 2005; Barros and Deitmer 2010). A nonexclusive, fast mechanism of neuronal fueling is lactate/pyruvate exchange, which transfers one reducing equivalent per cycle from astrocytes to neurons (Cerdan et al. 2006; Hung et al. 2011). It is not clear, at this stage, to what extent neurons are energized by the ANLS, redox cycling, or glucose. Also unclear is the relative contribution from each of the three fueling mechanisms in neuronal subtypes, across brain regions, and in response to neural activity.

Astrocytes store glycogen, the sole energy reserve of brain tissue. The brain does not express significant levels of glucose-6-phosphatase, so it cannot transform glycogen into glucose with high efficiency. However, glycogen can be transferred to neurons as lactate (Dringen et al. 1993). Glycogen breakdown is induced during hypoglycemia and ischemia (Brown and Ransom 2007; Oz et al. 2007, 2009; Matsui et al. 2012) and also under physiological conditions. In studies of optic nerve in vitro, firing was equally sustained by lactate or glucose (Brown et al. 2003) and impaired by pharmacological inhibition of glycogen phosphorylase, the enzyme that degrades glycogen (Tekkok et al. 2005). In vivo, glycogen phosphorylase inhibition caused amnesia (Gibbs et al. 2006; Newman et al. 2011; Suzuki et al. 2011), which was reverted by lactate (Newman et al. 2011; Suzuki et al. 2011). Moreover, lactate rescued the amnesic effect of knocking down the astrocytic lactate transporter MCT4, but not that of the neuronal lactate transporter MCT2, highlighting the transfer of lactate from astrocytes to neurons (Suzuki et al. 2011). Several neuronal signals are capable of mobilizing glycogen, including noradrenaline, adenosine, and vasoactive intestinal peptide (VIP), although glutamate proved ineffective (Sorg and Magistretti 1991). A link between local synaptic activity and glycogen mo- bilization was suggested recently, based on the observation that glycogen may be mobilized by elevated extracellular $\mathrm{K}^{+}$via the bicarbonatesensitive soluble adenylyl cyclase (Choi et al. 2012). Intriguingly, a sizable fraction of the glucose captured by astrocytes may be converted to glycogen before being metabolized to pyruvate, a phenomenon termed the "glycogen shunt" (Shulman et al. 2001; Walls et al. 2009).

\section{Energization of Intercellular Cycles}

Astrocytic intervention in neuronal metabolism also occurs via a prominent participation in the recycling of neurotransmitters and other molecules. Instead of being recaptured directly by neurons, most of the glutamate released during synaptic activity is diverted to astrocytes via high-affinity excitatory amino acid transporters (EAATs), converted to glutamine, and then shuttled back by the concerted work of multiple glutamine transporters (Deitmer et al. 2003; Bak et al. 2006). Because of the additional steps, the cycle becomes more expensive, but the burden is on astrocytes, allowing neurons to reduce their direct ATP investment in glutamate recycling by $60 \% .^{3}$ Further, neurons are spared the logistics of expressing the exceedingly high density of transporters required for fast glutamate removal (Rusakov and Kullmann 1998). $\gamma$-aminobutyric acid (GABA), dopamine, and noradrenalin are other neurotransmitters that are released by active neurons and recycled via astrocytes.

\section{Supply of Building Blocks}

Krebs cycle intermediates are the starting material for the synthesis of several classes of structural molecules, including fatty acids, sterols, amino acids, and porphyrins. Astrocytes replenish their own pool of Krebs intermediates, a process termed anaplerosis, by carboxylating

\footnotetext{
${ }^{3}$ The glutamate transporters import $3 \mathrm{Na}^{+}$and $1 \mathrm{H}^{+}$, requiring the use of 1.33 ATP molecules. The neuronal glutamine transporter SNAT imports $1 \mathrm{Na}^{+}$, requiring $0.33 \mathrm{ATP}$ molecules. These expenditures add to the $1 \mathrm{H}^{+}(0.33$ ATPs $)$ used by the vesicular glutamate transporter.
} 
glycolytic pyruvate to oxaloacetate (OAA). Neurons do not express pyruvate carboxylase and, for anaplerosis, they rely on glutamine imported from astrocytes, which is converted to glutamate and then into the Krebs intermediate $\alpha$ ketoglutarate (Yu et al. 1983; Schousboe et al. 1997). Thus, the building blocks for neuronal biosynthesis come from astrocytes. In addition, the glutamate/glutamine cycle is leaky, as some glutamate gets oxidized. Again, the losses of glutamate and glutamine are compensated by astrocytic anaplerosis. An estimated 33\%-50\% of all pyruvates entering mitochondria in astrocytes serve anaplerosis instead of producing energy (Hertz and Dienel 2002; Hyder et al. 2006). The export of molecules from astrocytes to neurons may also occur at higher levels. For instance, based on the differential expression of enzymes involved in the synthesis, export, and degradation of cholesterol, it has been suggested that astrocytes are net producers of cholesterol and neurons are net consumers (Pfrieger and Ungerer 2011). The brain pool of cholesterol, a major constituent of neuronal membranes, is completely isolated from the rest of the body. Oligodendrocytes have received less attention and it is not clear whether they are capable of anaplerosis or whether they rely on astrocytes (Amaral et al. 2013). The synthesis of myelin does seem to involve astrocytes as it is stimulated by lactate (Rinholm et al. 2011) and also by $N$-acetylaspartate (NAA), a highly abundant neuronal metabolite that is synthesized from glutamine imported from astrocytes (Amaral et al. 2013). Little is known about the metabolism of microglia and their likely metabolic exchange with astrocytes and/or neurons. Capable of proliferation and strong nicotinamide adenine dinucleotide phosphate (NADPH) oxidase activity, microglia are presumed to metabolize glucose at high rates. However, their hexose transporter is GLUT5, which, in humans, does not transport glucose but fructose (Augustin 2010), a sugar, which is almost absent in blood and cerebrospinal fluid. On activation, microglia augment their expression of MCT1 and MCT2 (Moreira et al. 2009), but it is not known whether they are lactate importers or exporters.

\section{Waste Recycling}

The most abundant waste products of neuronal activity are $\mathrm{CO}_{2}$, reactive oxygen species (ROS), ammonia $\left(\mathrm{NH}_{3}\right)$, and $\mathrm{K}^{+}$. Although $\mathrm{CO}_{2}$ diffuses across astrocytes into the blood and ROS are scavenged in situ, $\mathrm{NH}_{3}$ and $\mathrm{K}^{+}$are temporarily retained by astrocytes and then returned to neurons. $\mathrm{NH}_{3}$ is a gas that is stoichiometrically released during the glutamate and GABA cycles and when glutamine is used for anaplerosis. In the neuronal cytosol, $\mathrm{NH}_{3}$ captures a proton and becomes ammonium $\left(\mathrm{NH}_{4}{ }^{+}\right)$, equilibrating at a ratio of 100:1 $\left(\mathrm{NH}_{4}{ }^{+}: \mathrm{NH}_{3}\right)$. Lacking glutamine synthase, neurons cannot process the excess of nitrogen, which returns to astrocytes as $\mathrm{NH}_{4}{ }^{+}, \mathrm{NH}_{3}$, or in the form of amino acids (Fig. 1) (Bak et al. 2006; Cooper 2012; Rothman et al. 2012). $\mathrm{NH}_{4}{ }^{+}$enters astrocytes through $\mathrm{K}^{+}$channels and transporters (Nagaraja and Brookes 1998; Kelly and Rose 2010) to be returned to neurons as glutamine. This recycling and detoxifying mechanism, which works efficiently at the normal micromolar levels of $\mathrm{NH}_{4}{ }^{+}$, becomes overloaded during hyperammonemia. Competition between $\mathrm{NH}_{4}^{+}$and $\mathrm{K}^{+}$for channel-mediated uptake increases interstitial $\mathrm{K}^{+}$, leading to NKCC1-mediated neuronal disinhibition and neurotoxicity (Rangroo Thrane et al. 2013). During chronic hyperammonemia, astrocytes adapt to the excess $\mathrm{NH}_{4}{ }^{+}$by accumulating glutamine, which is released back into the bloodstream. However, high glutamine levels eventually damage the mitochondria and cause astrocytic swelling, leading to Alzheimer type II astrocytosis, the histochemical signature of hepatic encephalopathy (Albrecht and Norenberg 2006; Brusilow et al. 2010).

Other important waste products of brain cells derive from glutathione (GSH) and ascorbate (AA). GSH participates in the detoxification of ROS, endogenous toxins, and xenobiotics. Most of the oxidized glutathione (SGGS) is reduced in situ, but a minor fraction is lost via multidrug resistance (MDR) proteins, which also mediate the export of conjugated glutathione (GS-X). These losses are replenished by de novo synthesis of GSH, which, in neurons, is limited by cysteine supplied by astrocytes 
(Fig. 1) (Schmidt and Dringen 2012). AA (vitamin C) is a cofactor for many enzymatic reactions and is the most abundant free-radical scavenger in neurons. After oxidation by ROS, AA is reduced locally by reactions consuming $\mathrm{NAD}(\mathrm{P}) \mathrm{H}$, but some ends up as dehydroascorbic acid (DHA), a toxic compound that diffuses to astrocytes via glucose transporters to be recycled into AA by GSH or enzymatic reduction. The loop is completed in an activity-dependent manner by the export of AA via swelling-activated ion channels, followed by accumulation in neurons via the $\mathrm{Na}^{+}$-dependent AA cotransporter SVCT2 (Fig. 1) (Siushansian et al. 1996; Harrison and May 2009). Metabolism also generates toxins that are not free radicals, for example, methylglyoxal, an inevitable side product of glycolysis that promotes the formation of advanced glycation end (AGE) products and slowly progressing cell degeneration. As expected from their high rate of glycolysis, astrocytes express a robust glyoxalase system (Fig. 1) that protects both themselves and neurons against methylglyoxal toxicity (Belanger et al. 2011b).

\section{MEASURING METABOLISM, TOWARD SINGLE-CELL READOUTS}

New discoveries are often associated with methodological advances. It is remarkable to see how new techniques for visualizing structures or processes have influenced the way neuroscientists design experiments and formulate questions. This, too, is true for the astrocytic involvement in brain metabolism, and it is very likely that imaging techniques will become the forefront method in this field.

Studies of brain metabolism span a wide range, from the behavior of single enzymes using molecular dynamics to the long-term variation of brain glucose consumption in aging individuals. Glial involvement was first studied in vitro, which enables optimal control of experimental variables. Neuron and astrocyte cultures, in combination with radiolabeled substrate analogs, have been instrumental for the identification of molecular mechanisms. Strong small-scale interactions and mechanisms are relatively insensitive to large-scale context, thus the success of the reductionist in vitro approach. However, in cultured conditions, some specific boundary conditions are lost. For example, although the biophysical properties of a neuronal ion channel are insensitive to blood flow, hemodynamics may only be understood within the context of the intact tissue. To understand the concerted processes of brain energy metabolism involving neurons, glial cells, and blood vessels, in vivo experiments are essential.

Kety and Schmidt (1948) introduced one of the most influential early techniques to quantify global cerebral blood flow and metabolic rate in vivo. The method measures arteriovenous differences in the concentration of a tracer and is based on the brain absorbing an inert diffusible gas from arterial blood in a manner that only depends on perfusion. Sokoloff et al. (1977) took the next big step, developing the deoxyglucose method for measuring the local metabolic rate of glucose with autoradiography. A noninvasive variation of this technique soon became applicable to human subjects with the introduction of PET (Raichle et al. 1978). Resolution at cell level is now possible using cell-specific labeled compounds, such as acetate, which is unambiguously taken up by astrocytes (Waniewski and Martin 1998). Apart from chromatographic separation of metabolites from lysates and, subsequently, scintillation counting, $\left[{ }^{14} \mathrm{C}\right]$ labeled acetate has frequently been used together with autoradiography to map astrocytic metabolism (Muir et al. 1986; Dienel et al. 2001). On the basis of this method, an activity-dependent regulation of oxidative metabolism in astrocytes has been shown (Cruz et al. 2005), which was later replicated using the PET-tracer $\left[1-{ }^{11} \mathrm{C}\right]$-acetate in rat and human (Wyss et al. 2009). Acetate can also be labeled with the stable isotope $\left[{ }^{13} \mathrm{C}\right]$ for nuclear magnetic resonance (NMR) spectroscopy. In contrast to radiotracer-based methods, $\left[{ }^{13} \mathrm{C}\right]-\mathrm{NMR}$ spectroscopy presents a substantial advance with respect to the identification of metabolic products. With the appropriate kinetic models, the observed dynamics of the $\left[{ }^{13} \mathrm{C}\right]$-label in metabolic pathways permits quantitative determination of flux rates. Although individual fluxes in neurons and as- 
trocytes require assumptions with $\left[{ }^{13} \mathrm{C}\right]$-glucose, separation with the astrocyte-specific $\left[{ }^{13} \mathrm{C}\right]$-acetate is more direct. For example, using $\left[2-{ }^{13} \mathrm{C}\right]$-acetate, flux through the astrocytic Krebs cycle was found to be $0.14 \pm 0.06 \mathrm{mmol}$ per gram per minute, accounting for $\sim 15 \%$ total cerebral oxidative flux (Lebon et al. 2002). This flux is two times higher than that measured using $\left[{ }^{13} \mathrm{C}\right]$-glucose, reflecting glucose entry into neurons and astrocytes and mixing of labels between the cell types because of glutamate/glutamine cycling. Apart from a low spatial and temporal resolution, low sensitivity is another serious disadvantage of NMR spectroscopy. Consequently, a high concentration of label is required, which alters metabolic fluxes. This difficulty may, in part, be overcome with dynamic nuclear polarization (Mayer et al. 2009; Park et al. 2013).

All of the above-mentioned methods fail to resolve single cells, which is a severe drawback for the investigation of heterogeneous tissues, like the brain. Fluorescence optical imaging, confocal, as well as two-photon microscopy, achieve subcellular resolution and have made important contributions to glial research. Metabolism may also be investigated at cellular resolution with fluorescent glucose analogs, such as 6-NBDG and 2-NBDG, which probe glucose transport and consumption (Kim et al. 2012). Although these large molecules are transported and metabolized much more slowly than glucose, they still serve as tracers for studies in vitro and in vivo (Loaiza et al. 2003; Rouach et al. 2008; Barros et al. 2009a; Chuquet et al. 2010).

Genetically encoded fluorescent sensors specific for energy metabolites, glucose, glutamate, ATP, NADH, lactate, and pyruvate have been successfully used in brain cells and brain slices (reviewed in San Martín et al. 2014). Providing high spatiotemporal resolution, these sensors report cell-specific metabolite levels, absolute concentrations, and even metabolic fluxes, and are instrumental for the discovery of new phenomena and their molecular underpinnings. One example is the NBCe1-dependent stimulation of astrocytic glycolysis within seconds of an increase in extracellular $\mathrm{K}^{+}$, that is, within the time frame of the activity-dependent lactate surge detected in brain tissue (Barros 2013). Sensors continue to be developed and optimized in terms of dynamic range and signal-to-noise ratio, which, together with new protein expression strategies and imaging techniques, are permitting the subcellular, subsecond characterization of brain metabolism.

\section{CONCLUDING REMARKS}

We have outlined the central role of astrocytes in brain metabolism. To conclude, we would like to highlight four areas related to metabolic processes and astrocytes, which are not dealt with in the review. All four areas are currently in the spotlight and we believe that their significance will increase.

\section{Diversity}

Various types of neurons have been identified and it is well accepted that a "standard neuron" does not exist. Indeed, attempts to establish a unifying systematic taxonomy of neurons have been made ( for a recent classification scheme of GABAergic interneurons, see DeFelipe et al. 2013). Different types of astrocytes can also be distinguished, according to morphology, electrophysiological properties, and expression of specific proteins (Kimelberg 2009), so it seems likely that different metabolic phenotypes may also exist. The metabolic machinery of astrocytes is likely to differ in its relationship with the vasculature, in gap junctional communication with other astrocytes and oligodendrocytes, between brain areas, within species, and during development and in pathophysiology. The advent of single-cell resolution metabolic analysis will certainly shed more light on the metabolic diversity of astrocytes.

\section{The Oligodendrocyte: The Other Astrocyte of Energy Metabolism?}

Oligodendrocytes are responsible for the myelination of axons in the CNS, which forms the basis of efficient transmission of action potentials over long distances. In this context, oligo- 
dendrocytes have long been known to support axonal functioning. Recent research now indicates that oligodendrocytes, much like astrocytes, also play a pivotal role in metabolism, particularly with respect to energizing axons (Saab et al. 2013). More specifically, inactivation of oxidative metabolism in oligodendrocytes through conditional knockout of the Cox 10 gene failed to have a detrimental effect on cell functioning even in the long term. This strongly suggests that oligodendrocytes rely on aerobic glycolysis (Funfschilling et al. 2012). Moreover, oligodendrocytes were also shown to release lactate, which may fuel axons. An experimentally disrupted expression of MCT1, normally abundantly expressed in oligodendrocytes but also reduced in patients suffering from amyotrophic lateral sclerosis, leads to axonal degeneration (Lee et al. 2012). This negative effect is likely caused by the inability of oligodendrocytes to transport lactate and coincides with the hypothesis that oligodendrocyte-derived lactate is channeled through the myelin sheath and taken up by axons as an oxidative energy substrate. Oligodendrocytes show relatively low expression of glycolytic enzymes, but they communicate with astrocytes through gap junctions that are essential for myelin maintenance, suggesting substantial transfer of lactate and other metabolites between the two cell types (Tress et al. 2012).

\section{Metabolism and Signaling}

Mainstream neuroscience regards metabolism as a low-level domain, that is, an important but ultimately contingent platform that becomes interesting for information processing only when it goes wrong. However, there may be a more horizontal relationship between metabolism and signaling. Whereas brain tissue is energetically expensive, the process of encephalization occurred in a context of chronic food shortage, which implies that energy metabolism is a source of constraint for the evolutionary design of the brain (Aiello and Wheeler 1995; Navarrete et al. 2011). Moreover, metabolism and signaling share critical hubs, the most prominent example being glutamate, the main excitatory neurotransmitter, and also a pivotal metabolic intermediate.

Metabolism and signaling could have been kept separate, as exemplified by serotonin, acetylcholine, and noradrenalin neurotransmission, but they were not. Why? Another link between signaling and metabolism is adenosine, a degradation product of purine nucleotides but also a major neuromodulator involved in the coordination of synaptic networks, neurovascular coupling, and the physiology of sleep (Pascual et al. 2005; Blutstein and Haydon 2013). Further, cross talk is provided by lactate, which diffuses beyond the active zone and modifies the activity of neurons and astrocytes in neighboring regions acting via the $\mathrm{NADH} / \mathrm{NAD}^{+}$ratio, ion channels, and the $\mathrm{G}$ protein-coupled lactate receptor HCA1. Involved in a hierarchy of processes from neurovascular coupling to memory formation, lactate is both fuel and intercellular messenger (Suzuki et al. 2011; Barros 2013; Bozzo et al. 2013; Lauritzen et al. 2013; Tang et al. 2014). One defining characteristic of metabolic signals, like adenosine and lactate, is that they are local, conveying information to neighboring neuronal units and possibly helping to distribute resources between adjacent areas of the brain.

\section{The "Selfish" Astrocyte}

Outsourcing of metabolic processes makes neurons more efficient signaling machines, but also renders them vulnerable to potential deficits in astrocytic function. In response to metabolic or oxidative stress, astrocytes become "reactive" or "gliotic," terms that describe a phenotype characterized by cytoskeletal rearrangements, hypertrophy, loss of structural complexity, changes in metabolism, and secretion of inflammatory cytokines. Gliosis is an adaptive response, instrumental to the effective containment of acute injury and wound repair, but it may become harmful if astrocytes neglect their supportive role toward neurons, as is suspected to occur in chronic conditions, such as Alzheimer's disease. The metabolism of reactive astrocytes is not well understood, particularly in 
vivo, and may prove to be a relevant target for therapeutic intervention (Allaman et al. 2011; Steele and Robinson 2012).

\section{ACKNOWLEDGMENTS}

We are grateful to our colleagues for their continuing support and discussions. We thank Dr. Karen Everett for critical reading of the manuscript. This work is partly supported by Fondecyt Grant 1130095 and the Swiss National Science Foundation. The Centro de Estudios Científicos (CECs) is funded by the Chilean Government through the Centers of Excellence Basal Financing Program of La Comisión Nacional de Investigación Científica y Tecnológica (CONICYT).

\section{REFERENCES}

Aiello LC, Wheeler P. 1995. The expensive-tissue hypothesis The brain and the digestive system in human and primate evolution. Curr Anthropol 36: 199-221.

Albrecht J, Norenberg MD. 2006. Glutamine: ATrojan horse in ammonia neurotoxicity. Hepatology 44: 788-794.

Allaman I, Belanger M, Magistretti PJ. 2011. Astrocyte-neuron metabolic relationships: For better and for worse. Trends Neurosci 34: 76-87.

Amaral AI, Meisingset TW, Kotter MR, Sonnewald U. 2013. Metabolic aspects of neuron-oligodendrocyte-astrocyte interactions. Front Endocrinol (Lausanne) 4: 54.

Araque A, Parpura V, Sanzgiri RP, Haydon PG. 1999. Tripartite synapses: Glia, the unacknowledged partner. Trends Neurosci 22: 208-215.

Attwell D, Laughlin SB. 2001. An energy budget for signaling in the grey matter of the brain. J Cereb Blood Flow Metab 21: 1133-1145.

Aubert A, Costalat R, Magistretti PJ, Pellerin L. 2005. Brain lactate kinetics: Modeling evidence for neuronal lactate uptake upon activation. Proc Natl Acad Sci 102: 1644816453.

Augustin R. 2010. The protein family of glucose transport facilitators: It's not only about glucose after all. IUBMB Life 62: 315-333.

Azarias G, Perreten H, Lengacher S, Poburko D, Demaurex N, Magistretti PJ, Chatton JY. 2011. Glutamate transport decreases mitochondrial $\mathrm{pH}$ and modulates oxidative metabolism in astrocytes. J Neurosci 31: 35503559.

Bak LK, Schousboe A, Waagepetersen HS. 2006. The glutamate/GABA-glutamine cycle: Aspects of transport, neurotransmitter homeostasis and ammonia transfer. $J \mathrm{Neu}$ rochem 98: 641-653.

Barros LF. 2013. Metabolic signaling by lactate in the brain. Trends Neurosci 36: 396-404.
Barros LF, Deitmer JW. 2010. Glucose and lactate supply to the synapse. Brain Res Rev 63: 149-159.

Barros LF, Martinez C. 2007. An enquiry into metabolite domains. Biophys J 92: 3878-3884.

Barros LF, Bittner CX, Loaiza A, Ruminot I, Larenas V, Moldenhauer H, Oyarzun C, Alvarez M. 2009a. Kinetic validation of 6-NBDG as a probe for the glucose transporter GLUT1 in astrocytes. J Neurochem 109: 94-100.

Barros LF, Courjaret R, Jakoby P, Loaiza A, Lohr C, Deitmer JW. 2009b. Preferential transport and metabolism of glucose in Bergmann glia over Purkinje cells: A multiphoton study of cerebellar slices. Glia 57: 962-970.

Belanger M, Allaman I, Magistretti PJ. 2011a. Brain energy metabolism: Focus on astrocyte-neuron metabolic cooperation. Cell Metab 14: 724-738.

Belanger M, Yang J, Petit JM, Laroche T, Magistretti PJ, Allaman I. 2011b. Role of the glyoxalase system in astrocytemediated neuroprotection. J Neurosci 31: 18338-18352.

Bernardinelli Y, Muller D, Nikonenko I. 2014a. Astrocytesynapse structural plasticity. Neural Plast 2014: 232105.

Bernardinelli Y, Randall J, Janett E, Nikonenko I, Konig S, Jones EV, Flores CE, Murai KK, Bochet CG, Holtmaat A, et al. 2014b. Activity-dependent structural plasticity of perisynaptic astrocytic domains promotes excitatory synapse stability. Curr Biol 24: 1679-1688.

Bittner CX, Loaiza A, Ruminot I, Larenas V, Sotelo-Hitschfeld T, Gutierrez R, Cordova A, Valdebenito R, Frommer WB, Barros LF. 2010. High resolution measurement of the glycolytic rate. Front Neuroenergetics 2: 26.

Bittner CX, Valdebenito R, Ruminot I, Loaiza A, Larenas V, Sotelo-Hitschfeld T, Moldenhauer H, San Martin A, Gutierrez R, Zambrano M, et al. 2011. Fast and reversible stimulation of astrocytic glycolysis by $\mathrm{K}^{+}$and a delayed and persistent effect of glutamate. J Neurosci 31: 47094713.

Blinder P, Tsai PS, Kaufhold JP, Knutsen PM, Suhl H, Kleinfeld D. 2013. The cortical angiome: An interconnected vascular network with noncolumnar patterns of blood flow. Nat Neurosci 16: 889-897.

Blutstein T, Haydon PG. 2013. The importance of astrocytederived purines in the modulation of sleep. Glia 61 : 129139.

Bouzier-Sore AK, Voisin P, Canioni P, Magistretti PJ, Pellerin L. 2003. Lactate is a preferential oxidative energy substrate over glucose for neurons in culture. J Cereb Blood Flow Metab 23: 1298-1306.

Bouzier-Sore AK, Voisin P, Bouchaud V, Bezancon E, Franconi JM, Pellerin L. 2006. Competition between glucose and lactate as oxidative energy substrates in both neurons and astrocytes: A comparative NMR study. Eur J Neurosci 24: $1687-1694$.

Bozzo L, Puyal J, Chatton JY. 2013. Lactate modulates the activity of primary cortical neurons through a receptormediated pathway. PloS ONE 8: e71721.

Brown AM, Ransom BR. 2007. Astrocyte glycogen and brain energy metabolism. Glia 55: 1263-1271.

Brown AM, Tekkok SB, Ransom BR. 2003. Glycogen regulation and functional role in mouse white matter. $J$ Physiol 549: 501-512.

Brusilow SW, Koehler RC, Traystman RJ, Cooper AJ. 2010. Astrocyte glutamine synthetase: Importance in hyperam- 
monemic syndromes and potential target for therapy. Neurotherapeutics 7: 452-470.

Bushong EA, Martone ME, Jones YZ, Ellisman MH. 2002. Protoplasmic astrocytes in CA1 stratum radiatum occupy separate anatomical domains. J Neurosci 22: 183-192.

Cahoy JD, Emery B, Kaushal A, Foo LC, Zamanian JL, Christopherson KS, Xing Y, Lubischer JL, Krieg PA, Krupenko SA, et al. 2008. A transcriptome database for astrocytes, neurons, and oligodendrocytes: A new resource for understanding brain development and function. J Neurosci 28: 264-278.

Cerdan S, Rodrigues TB, Sierra A, Benito M, Fonseca LL, Fonseca CP, Garcia-Martin ML. 2006. The redox switch/ redox coupling hypothesis. Neurochem Int 48: 523-530.

Choi HB, Gordon GR, Zhou N, Tai C, Rungta RL, Martinez J, Milner TA, Ryu JK, McLarnon JG, Tresguerres M, et al. 2012. Metabolic communication between astrocytes and neurons via bicarbonate-responsive soluble adenylyl cyclase. Neuron 75: 1094-1104.

Chuquet J, Quilichini P, Nimchinsky EA, Buzsaki G. 2010 Predominant enhancement of glucose uptake in astrocytes versus neurons during activation of the somatosensory cortex. J Neurosci 30: 15298-15303.

Cooper AJ. 2012. The role of glutamine synthetase and glutamate dehydrogenase in cerebral ammonia homeostasis. Neurochem Res 37: 2439-2455.

Cruz NF, Lasater A, Zielke HR, Dienel GA. 2005. Activation of astrocytes in brain of conscious rats during acoustic stimulation: Acetate utilization in working brain. $\mathrm{J} \mathrm{Neu-}$ rochem 92: 934-947.

Dalsgaard MK, Quistorff B, Danielsen ER, Selmer C, Vogelsang T, Secher NH. 2004. A reduced cerebral metabolic ratio in exercise reflects metabolism and not accumulation of lactate within the human brain. J Physiol 554: 571-578.

DeFelipe J, Lopez-Cruz PL, Benavides-Piccione R, Bielza C, Larranaga P, Anderson S, Burkhalter A, Cauli B, Fairen A, Feldmeyer D, et al. 2013. New insights into the classification and nomenclature of cortical GABAergic interneurons. Nat Rev Neurosci 14: 202-216.

Deitmer JW, Broer A, Broer S. 2003. Glutamine efflux from astrocytes is mediated by multiple pathways. J Neurochem 87: 127-135.

Derouiche A, Frotscher M. 2001. Peripheral astrocyte processes: Monitoring by selective immunostaining for the actin-binding ERM proteins. Glia 36: 330-341.

Dienel GA, Liu K, Cruz NF. 2001. Local uptake of ${ }^{14} \mathrm{C}-\mathrm{la}$ beled acetate and butyrate in rat brain in vivo during spreading cortical depression. J Neurosci Res 66: 812820.

Dringen R, Gebhardt R, Hamprecht B. 1993. Glycogen in astrocytes: Possible function as lactate supply for neighboring cells. Brain Res 623: 208-214.

Fernandez-Fernandez S, Almeida A, Bolanos JP. 2012. Antioxidant and bioenergetic coupling between neurons and astrocytes. Biochem J 443: 3-11.

Funfschilling U, Supplie LM, Mahad D, Boretius S, Saab AS, Edgar J, Brinkmann BG, Kassmann CM, Tzvetanova ID, Mobius W, et al. 2012. Glycolytic oligodendrocytes maintain myelin and long-term axonal integrity. Nature 485: 517-521.
Giaume C, Koulakoff A, Roux L, Holcman D, Rouach N. 2010. Astroglial networks: A step further in neuroglial and gliovascular interactions. Nat Rev Neurosci 11: 87-99.

Gibbs ME, Anderson DG, Hertz L. 2006. Inhibition of glycogenolysis in astrocytes interrupts memory consolidation in young chickens. Glia 54: 214-222.

Grosche J, Matyash V, Moller T, Verkhratsky A, Reichenbach A, Kettenmann H. 1999. Microdomains for neuron-glia interaction: Parallel fiber signaling to Bergmann glial cells. Nat Neurosci 2: 139-143.

Haj-Yasein NN, Vindedal GF, Eilert-Olsen M, Gundersen GA, Skare O, Laake P, Klungland A, Thoren AE, Burkhardt JM, Ottersen OP, et al. 2011. Glial-conditional deletion of aquaporin-4 (Aqp4) reduces blood-brain water uptake and confers barrier function on perivascular astrocyte endfeet. Proc Natl Acad Sci 108: 17815-17820.

Halassa MM, Haydon PG. 2010. Integrated brain circuits: Astrocytic networks modulate neuronal activity and behavior. Annu Rev Physiol 72: 335-355.

Halassa MM, Fellin T, Takano H, Dong JH, Haydon PG. 2007. Synaptic islands defined by the territory of a single astrocyte. J Neurosci 27: 6473-6477.

Halim ND, McFate T, Mohyeldin A, Okagaki P, Korotchkina LG, Patel MS, Jeoung NH, Harris RA, Schell MJ, Verma A. 2010. Phosphorylation status of pyruvate dehydrogenase distinguishes metabolic phenotypes of cultured rat brain astrocytes and neurons. Glia 58: 1168-1176.

Harris JJ, Jolivet R, Attwell D. 2012. Synaptic energy use and supply. Neuron 75: 762-777.

Harrison FE, May JM. 2009. Vitamin C function in the brain: Vital role of the ascorbate transporter SVCT2. Free Radic Biol Med 46: 719-730.

Herrero-Mendez A, Almeida A, Fernandez E, Maestre C, Moncada S, Bolanos JP. 2009. The bioenergetic and antioxidant status of neurons is controlled by continuous degradation of a key glycolytic enzyme by APC/C-Cdh1. Nat Cell Biol 11: 747-752.

Hertz L, Dienel GA. 2002. Energy metabolism in the brain. Int Rev Neurobiol 51: 1-102.

Hirsch S, Reichold J, Schneider M, Szekely G, Weber B. 2012. Topology and hemodynamics of the cortical cerebrovascular system. J Cereb Blood Flow Metab 32: 952-967.

Houades V, Koulakoff A, Ezan P, Seif I, Giaume C. 2008. Gap junction-mediated astrocytic networks in the mouse barrel cortex. J Neurosci 28: 5207-5217.

Hung YP, Albeck JG, Tantama M, Yellen G. 2011. Imaging cytosolic NADH-NAD ${ }^{+}$redox state with a genetically encoded fluorescent biosensor. Cell Metab 14: 545-554.

Hyder F, Patel AB, Gjedde A, Rothman DL, Behar KL, Shulman RG. 2006. Neuronal-glial glucose oxidation and glutamatergic-GABAergic function. J Cereb Blood Flow Metab 26: 865-877.

Iliff JJ, Nedergaard M. 2013. Is there a cerebral lymphatic system? Stroke 44: S93-S95.

Iliff JJ, Wang M, Liao Y, Plogg BA, Peng W, Gundersen GA, Benveniste H, Vates GE, Deane R, Goldman SA, et al. 2012. A paravascular pathway facilitates CSF flow through the brain parenchyma and the clearance of interstitial solutes, including amyloid $\beta$. Sci Transl Med 4: 147ra111.

Iliff JJ, Wang M, Zeppenfeld DM, Venkataraman A, Plog BA, Liao Y, Deane R, Nedergaard M. 2013. Cerebral arterial 
pulsation drives paravascular CSF-interstitial fluid ex change in the murine brain. J Neurosci 33: 18190-18199.

Jakoby P, Schmidt E, Ruminot I, Gutierrez R, Barros LF, Deitmer JW. 2013. Higher transport and metabolism of glucose in astrocytes compared with neurons: A multiphoton study of hippocampal and cerebellar tissue slices. Cereb Cortex 24: 222-231.

Kacem K, Lacombe P, Seylaz J, Bonvento G. 1998. Structural organization of the perivascular astrocyte endfeet and their relationship with the endothelial glucose transporter: A confocal microscopy study. Glia 23: 1-10.

Keller AL, Schuz A, Logothetis NK, Weber B. 2011. Vascularization of cytochrome oxidase-rich blobs in the primary visual cortex of squirrel and macaque monkeys. $J$ Neurosci 31: 1246-1253.

Kelly T, Rose CR. 2010. Ammonium influx pathways into astrocytes and neurones of hippocampal slices. J Neurochem 115: 1123-1136.

Kety SS, Schmidt CF. 1948. Higher transport and metabolism of glucose in astrocytes compared with neurons: A multiphoton study of hippocampal and cerebellar tissue slices. J Clin Invest 27: 476-483.

Kim WH, Lee J, Jung DW, Williams DR. 2012. Visualizing sweetness: Increasingly diverse applications for fluorescent-tagged glucose bioprobes and their recent structural modifications. Sensors 12: 5005-5027.

Kimelberg HK. 2009. Astrocyte heterogeneity or homogeneity. In Astrocytes in (patho) physiology of the nervous system (ed. Parpura V, Haydon PG), pp. 1-26. Springer, New York.

Kording KP, Kayser C, Konig P. 2003. On the choice of a sparse prior. Rev Neurosci 14: 53-62.

Kreft M, Luksic M, Zorec TM, Prebil M, Zorec R. 2013. Diffusion of D-glucose measured in the cytosol of a single astrocyte. Cell Mol Life Sci 70: 1483-1492.

Lauritzen KH, Morland C, Puchades M, Holm-Hansen S, Hagelin EM, Lauritzen F, Attramadal H, Storm-Mathisen J, Gjedde A, Bergersen LH. 2013. Lactate receptor sites link neurotransmission, neurovascular coupling, and brain energy metabolism. Cereb Cortex 24: 2784-2795.

Lebon V, Petersen KF, Cline GW, Shen J, Mason GF, Dufour S, Behar KL, Shulman GI, Rothman DL. 2002. Astroglial contribution to brain energy metabolism in humans revealed by $13 \mathrm{C}$ nuclear magnetic resonance spectroscopy: Elucidation of the dominant pathway for neurotransmitter glutamate repletion and measurement of astrocytic oxidative metabolism. J Neurosci 22: 1523-1531.

Lee Y, Morrison BM, Li Y, Lengacher S, Farah MH, Hoffman PN, Liu Y, Tsingalia A, Jin L, Zhang PW, et al. 2012 Oligodendroglia metabolically support axons and contribute to neurodegeneration. Nature 487: 443-448.

Li WE, Ochalski PA, Hertzberg EL, Nagy JI. 1998. Immunorecognition, ultrastructure and phosphorylation status of astrocytic gap junctions and connexin 43 in rat brain after cerebral focal ischaemia. Eur J Neurosci 10: $2444-$ 2463.

Loaiza A, Porras OH, Barros LF. 2003. Glutamate triggers rapid glucose transport stimulation in astrocytes as evidenced by real-time confocal microscopy. J Neurosci 23: 7337-7342.
Lovatt D, Sonnewald U, Waagepetersen HS, Schousboe A, He W, Lin JH, Han X, Takano T, Wang S, Sim FJ, et al. 2007. The transcriptome and metabolic gene signature of protoplasmic astrocytes in the adult murine cortex. $J$ Neurosci 27: 12255-12266.

Magistretti PJ. 2008. Brain energy metabolism. In Fundamental neuroscience (ed. Squire LR, Bloom FE, Spitzer NC, Du Lac S, Ghosh A, Berg D), pp. 271-293. Academic, New York.

Martinez C, Kalise D, Barros LF. 2010. General requirement for harvesting antennae at $\mathrm{Ca}^{2+}$ and $\mathrm{H}^{+}$channels and transporters. Front Neuroenergetics 2: 27.

Mathiisen TM, Lehre KP, Danbolt NC, Ottersen OP. 2010 The perivascular astroglial sheath provides a complete covering of the brain microvessels: An electron microscopic 3D reconstruction. Glia 58: 1094-1103.

Matsui T, Ishikawa T, Ito H, Okamoto M, Inoue K, Lee MC, Fujikawa T, Ichitani Y, Kawanaka K, Soya H. 2012. Brain glycogen supercompensation following exhaustive exercise. J Physiol 590: 607-616.

Mayer D, Yen YF, Tropp J, Pfefferbaum A, Hurd RE, Spielman DM. 2009. Application of subsecond spiral chemical shift imaging to real-time multislice metabolic imaging of the rat in vivo after injection of hyperpolarized 13C1pyruvate. Magn Reson Med 62: 557-564.

Moreira TJ, Pierre K, Maekawa F, Repond C, Cebere A, Liljequist S, Pellerin L. 2009. Enhanced cerebral expression of MCT1 and MCT2 in a rat ischemia model occurs in activated microglial cells. J Cereb Blood Flow Metab 29: 1273-1283.

Muir D, Berl S, Clarke DD. 1986. Acetate and fluoroacetate as possible markers for glial metabolism in vivo. Brain Res 380: $336-340$.

Nagaraja TN, Brookes N. 1998. Intracellular acidification induced by passive and active transport of ammonium ions in astrocytes. Am J Physiol 274: C883-C891.

Navarrete A, van Schaik CP, Isler K. 2011. Energetics and the evolution of human brain size. Nature 480: 91-93.

Newman LA, Korol DL, Gold PE. 2011. Lactate produced by glycogenolysis in astrocytes regulates memory processing. PloS ONE 6: e28427.

Nuriya M, Shinotsuka T, Yasui M. 2013. Diffusion properties of molecules at the blood-brain interface: Potential contributions of astrocyte endfeet to diffusion barrier functions. Cereb Cortex 23: 2118-2126.

Oberheim NA, Tian GF, Han X, Peng W, Takano T, Ransom B, Nedergaard M. 2008. Loss of astrocytic domain organization in the epileptic brain. J Neurosci 28: 3264-3276.

Obermeier B, Daneman R, Ransohoff RM. 2013. Development, maintenance and disruption of the blood-brain barrier. Nat Med 19: 1584-1596.

Oliet SH, Piet R, Poulain DA. 2001. Control of glutamate clearance and synaptic efficacy by glial coverage of neurons. Science 292: 923-926.

Olshausen BA, Field DJ. 2004. Sparse coding of sensory inputs. Curr Opin Neurobiol 14: 481-487.

Oz G, Seaquist ER, Kumar A, Criego AB, Benedict LE, Rao JP, Henry PG, Van De Moortele PF, Gruetter R. 2007. Human brain glycogen content and metabolism: Implications on its role in brain energy metabolism. Am J Physiol Endocrinol Metab 292: E946-E951. 
Oz G, Kumar A, Rao JP, Kodl CT, Chow L, Eberly LE, Seaquist ER. 2009. Human brain glycogen metabolism during and after hypoglycemia. Diabetes 58: 1978-1985.

Panatier A, Theodosis DT, Mothet JP, Touquet B, Pollegioni L, Poulain DA, Oliet SH. 2006. Glia-derived D-serine controls NMDA receptor activity and synaptic memory. Cell 125: 775-784.

Park JM, Josan S, Grafendorfer T, Yen YF, Hurd RE, Spielman DM, Mayer D. 2013. Measuring mitochondrial metabolism in rat brain in vivo using MR Spectroscopy of hyperpolarized $\left[2{ }^{13} \mathrm{C}\right]$ pyruvate. NMR Biomed 26: 1197-1203.

Pascual O, Casper KB, Kubera C, Zhang J, Revilla-Sanchez R, Sul JY, Takano H, Moss SJ, McCarthy K, Haydon PG 2005. Astrocytic purinergic signaling coordinates synaptic networks. Science 310: 113-116.

Pellerin L, Magistretti PJ. 1994. Glutamate uptake into astrocytes stimulates aerobic glycolysis: A mechanism coupling neuronal activity to glucose utilization. Proc Natl Acad Sci 91: 10625-10629.

Pfrieger FW, Ungerer N. 2011. Cholesterol metabolism in neurons and astrocytes. Prog Lipid Res 50: 357-371.

Porras OH, Ruminot I, Loaiza A, Barros LF. 2008. $\mathrm{Na}^{+}{ }_{-} \mathrm{Ca}^{2+}$ cosignaling in the stimulation of the glucose transporter GLUT1 in cultured astrocytes. Glia 56: 59-68.

Prebil M, Vardjan N, Jensen J, Zorec R, Kreft M. 2011. Dynamic monitoring of cytosolic glucose in single astrocytes. Glia 59: 903-913.

Raichle ME, Welch MJ, Grubb RL Jr, Higgins CS, Ter-Pogossian MM, Larson KB. 1978. Measurement of regional substrate utilization rates by emission tomography. Science 199: 986-987.

Rangroo Thrane V, Thrane AS, Wang F, Cotrina ML, Smith NA, Chen M, Xu Q, Kang N, Fujita T, Nagelhus EA, et al 2013. Ammonia triggers neuronal disinhibition and seizures by impairing astrocyte potassium buffering. Nat Med 19: $1643-1648$

Rasmussen P, Wyss MT, Lundby C. 2011. Cerebral glucose and lactate consumption during cerebral activation by physical activity in humans. FASEB J 25: 2865-2873.

Reichenbach A. 1989. Attempt to classify glial cells by means of their process specialization using the rabbit retinal Muller cell as an example of cytotopographic specialization of glial cells. Glia 2: 250-259.

Rinholm JE, Hamilton NB, Kessaris N, Richardson WD, Bergersen LH, Attwell D. 2011. Regulation of oligodendrocyte development and myelination by glucose and lactate. J Neurosci 31: 538-548.

Rothman DL, De Feyter HM, Maciejewski PK, Behar KL 2012. Is there in vivo evidence for amino acid shuttles carrying ammonia from neurons to astrocytes? Neurochem Res 37: 2597-2612.

Rouach N, Koulakoff A, Abudara V, Willecke K, Giaume C. 2008. Astroglial metabolic networks sustain hippocampal synaptic transmission. Science 322: 1551-1555.

Roux L, Benchenane K, Rothstein JD, Bonvento G, Giaume C. 2011. Plasticity of astroglial networks in olfactory glomeruli. Proc Natl Acad Sci 108: 18442-18446.

Ruminot I, Gutierrez R, Pena-Munzenmayer G, Anazco C, Sotelo-Hitschfeld T, Lerchundi R, Niemeyer MI, Shull GE, Barros LF. 2011. NBCe1 mediates the acute stimula- tion of astrocytic glycolysis by extracellular $\mathrm{K}^{+}$. J Neurosci 31: 14264-14271.

Rusakov DA, Kullmann DM. 1998. Extrasynaptic glutamate diffusion in the hippocampus: Ultrastructural constraints, uptake, and receptor activation. J Neurosci 18: 3158-3170.

Saab AS, Tzvetanova ID, Nave KA. 2013. The role of myelin and oligodendrocytes in axonal energy metabolism. Curr Opin Neurobiol 23: 1065-1072.

San Martín A, Sotelo-Hitschfeld T, Lerchundi R, FernándezMoncada I, Ceballo S, Valdebenito R, Baeza-Lehnert F Alegría K, Contreras-Baeza Y, Garrido-Gerter P, et al. 2014. Single-cell imaging tools for brain energy metabolism: A review. Neurophotonics 1: 011004.

Schmidt MM, Dringen R. 2012. GSH synthesis and metabolism. In Advances in neurobiology, Vol 4: Neural metabolism in vivo (ed. Gruetter R, Choi IY), pp. 1029-1050. Springer, New York.

Schousboe A, Westergaard N, Waagepetersen HS, Larsson OM, Bakken IJ, Sonnewald U. 1997. Trafficking between glia and neurons of TCA cycle intermediates and related metabolites. Glia 21: 99-105.

Schurr A, West CA, Rigor BM. 1988. Lactate-supported synaptic function in the rat hippocampal slice preparation. Science 240: 1326-1328.

Shulman RG, Hyder F, Rothman DL. 2001. Cerebral energetics and the glycogen shunt: Neurochemical basis of functional imaging. Proc Natl Acad Sci 98: 6417-6422.

Siesjö BK. 1978. Brain energy metabolism. Wiley, New York.

Siushansian R, Dixon SJ, Wilson JX. 1996. Osmotic swelling stimulates ascorbate efflux from cerebral astrocytes. $J$ Neurochem 66: 1227-1233.

Sokoloff L, Reivich M, Kennedy C, Des Rosiers MH, Patlak CS, Pettigrew KD, Sakurada O, Shinohara M. 1977. The $\left[{ }^{14} \mathrm{C}\right]$ deoxyglucose method for the measurement of local cerebral glucose utilization: Theory, procedure, and normal values in the conscious and anesthetized albino rat. $J$ Neurochem 28: 897-916.

Sorg O, Magistretti PJ. 1991. Characterization of the glycogenolysis elicited by vasoactive intestinal peptide, noradrenaline and adenosine in primary cultures of mouse cerebral cortical astrocytes. Brain Res 563: 227233.

Spacek J. 1985. Three-dimensional analysis of dendritic spines: III. Glial sheath. Anat Embryol (Berl) 171: 245 252.

Steele ML, Robinson SR. 2012. Reactive astrocytes give neurons less support: Implications for Alzheimer's disease. Neurobiol Aging 33: e421-e413.

Suzuki A, Stern SA, Bozdagi O, Huntley GW, Walker RH, Magistretti PJ, Alberini CM. 2011. Astrocyte-neuron lactate transport is required for long-term memory formation. Cell 144: 810-823.

Tang F, Lane S, Korsak A, Paton JFR, Gourine AV, Kasparov S, Teschemacher A. 2014. Lactate-mediated glia-neuronal signalling in the mammalian brain. Nat Comm 5: 3284

Tekkok SB, Brown AM, Westenbroek R, Pellerin L, Ransom BR. 2005. Transfer of glycogen-derived lactate from astrocytes to axons via specific monocarboxylate transport- 
ers supports mouse optic nerve activity. J Neurosci Res 81: $644-652$.

Tress O, Maglione M, May D, Pivneva T, Richter N, Seyfarth J, Binder S, Zlomuzica A, Seifert G, Theis M, et al. 2012. Panglial gap junctional communication is essential for maintenance of myelin in the CNS. J Neurosci 32: 7499-7518.

Tsai PS, Kaufhold JP, Blinder P, Friedman B, Drew PJ, Karten HJ, Lyden PD, Kleinfeld D. 2009. Correlations of neuronal and microvascular densities in murine cortex revealed by direct counting and colocalization of nuclei and vessels. J Neurosci 29: 14553-14570.

Ventura R, Harris KM. 1999. Three-dimensional relationships between hippocampal synapses and astrocytes. J Neurosci 19: 6897-6906.

Voutsinos-Porche B, Bonvento G, Tanaka K, Steiner P, Welker E, Chatton JY, Magistretti PJ, Pellerin L. 2003. Glial glutamate transporters mediate a functional metabolic crosstalk between neurons and astrocytes in the mouse developing cortex. Neuron 37: 275-286.

Walls AB, Heimburger CM, Bouman SD, Schousboe A Waagepetersen HS. 2009. Robust glycogen shunt activity in astrocytes: Effects of glutamatergic and adrenergic agents. Neuroscience 158: 284-292.
Waniewski RA, Martin DL. 1998. Preferential utilization of acetate by astrocytes is attributable to transport. J Neurosci 18: 5225-5233.

Weber B, Keller AL, Reichold J, Logothetis NK. 2008. The microvascular system of the striate and extrastriate visual cortex of the macaque. Cereb Cortex 18: 23182330.

Wyss MT, Weber B, Treyer V, Heer S, Pellerin L, Magistretti PJ, Buck A. 2009. Stimulation-induced increases of astrocytic oxidative metabolism in rats and humans investigated with $1-{ }^{11}$ C-acetate. J Cereb Blood Flow Metab 29: 44-56.

Wyss MT, Jolivet R, Buck A, Magistretti PJ, Weber B. 2011. In vivo evidence for lactate as a neuronal energy source. $J$ Neurosci 31: 7477-7485.

Xie L, Kang H, Xu Q, Chen MJ, Liao Y, Thiyagarajan M, O’Donnell J, Christensen DJ, Nicholson C, Iliff JJ, et al. 2013. Sleep drives metabolite clearance from the adult brain. Science 342: 373-377.

Yellen G. 2008. Ketone bodies, glycolysis, and KATP channels in the mechanism of the ketogenic diet. Epilepsia 49: 80-82.

Yu AC, Drejer J, Hertz L, Schousboe A. 1983. Pyruvate carboxylase activity in primary cultures of astrocytes and neurons. J Neurochem 41: 1484-1487. 


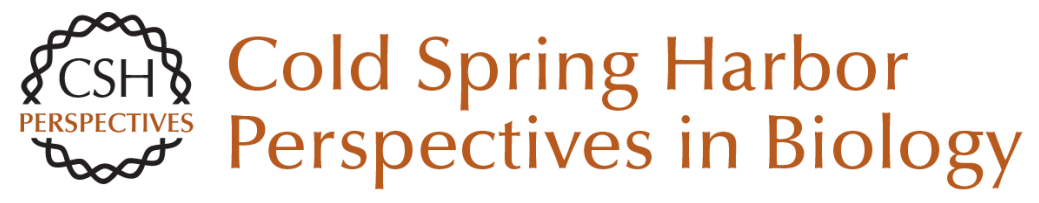

\section{The Astrocyte: Powerhouse and Recycling Center}

Bruno Weber and L. Felipe Barros

Cold Spring Harb Perspect Biol 2015; doi: 10.1101/cshperspect.a020396 originally published online February 13, 2015

\section{Subject Collection Glia}

The Nodes of Ranvier: Molecular Assembly and Maintenance

Matthew N. Rasband and Elior Peles

Microglia in Health and Disease

Richard M. Ransohoff and Joseph El Khoury

The Astrocyte: Powerhouse and Recycling Center Bruno Weber and L. Felipe Barros

Microglia Function in Central Nervous System

Development and Plasticity

Dorothy P. Schafer and Beth Stevens

Transcriptional and Epigenetic Regulation of Oligodendrocyte Development and Myelination in the Central Nervous System

Ben Emery and Q. Richard Lu

Origin of Microglia: Current Concepts and Past

Controversies

Florent Ginhoux and Marco Prinz

Glia Disease and Repair--Remyelination

Robin J.M. Franklin and Steven A. Goldman

Astrocytes in Neurodegenerative Disease

Hemali Phatnani and Tom Maniatis
Oligodendrocyte Development and Plasticity Dwight E. Bergles and William D. Richardson

Oligodendrocytes: Myelination and Axonal

Support Mikael Simons and Klaus-Armin Nave

Drosophila Central Nervous System Glia Marc R. Freeman

Perisynaptic Schwann Cells at the Neuromuscular

Synapse: Adaptable, Multitasking Glial Cells Chien-Ping Ko and Richard Robitaille

Astrocytes Control Synapse Formation, Function, and Elimination Won-Suk Chung, Nicola J. Allen and Cagla Eroglu

Schwann Cell Myelination James L. Salzer

Schwann Cells: Development and Role in Nerve Repair

Kristján R. Jessen, Rhona Mirsky and Alison C. Lloyd

Perineurial Glia

Sarah Kucenas

For additional articles in this collection, see http://cshperspectives.cshlp.org/cgi/collection/

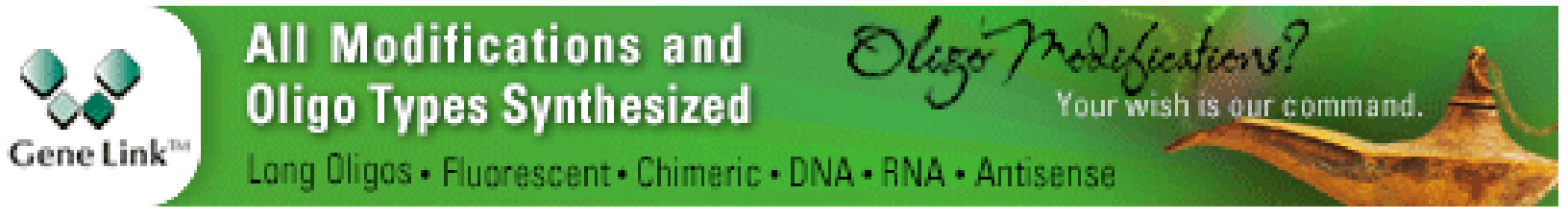

